\title{
Passive transfer of narcolepsy: Anti-TRIB2 autoantibody positive patient IgG causes hypothalamic orexin neuron loss and sleep attacks in mice
}

\author{
Aviva Katzav a,b,1, Maria T. Arango $^{\text {b,c,d,1 }}{ }^{\text {, Shaye Kivity }}{ }^{\text {b }}$, Susumu Tanaka ${ }^{\text {e }}$, Gili Givaty ${ }^{\text {a,b }}$, \\ Nancy Agmon-Levin ${ }^{\mathrm{b}}$, Makoto Honda ${ }^{\mathrm{e}}$, Juan-Manuel Anaya ${ }^{\mathrm{c}}$, Joab Chapman ${ }^{\mathrm{a}, \mathrm{b}}$, \\ Yehuda Shoenfeld ${ }^{\mathrm{b}, \mathrm{f}, *}$ \\ a Dept. Neurology and Sagol Neuroscience Center, Sheba Medical Center, Tel-Hashomer, Israel \\ ${ }^{\mathrm{b}}$ Zabludowicz Center for Autoimmune Diseases, Sheba Medical Center, Tel-Hashomer, Affiliated to Sackler Medical School, Tel Aviv University, Israel \\ ${ }^{c}$ Center for Autoimmune Diseases Research - CREA, Universidad del Rosario, Bogota, Colombia \\ ${ }^{\mathrm{d}}$ Doctoral Program in Biomedical Sciences, Universidad del Rosario, Bogota, Colombia \\ e The Sleep Control Project, Tokyo Metropolitan Institute of Psychiatry, Tokyo, Japan \\ ${ }^{\mathrm{f}}$ Incumbent of the Laura Schwarz-Kip Chair for Research of Autoimmune Diseases, Tel Aviv University, Israel
}

\section{A R T I C L E I N F O}

\section{Article history:}

Received 17 June 2013

Accepted 18 June 2013

\section{Keywords:}

Narcolepsy

Anti-Tribbles homolog 2 (TRIB2) antibodies

Passive transfer

Orexin

Behavioral deficits

\begin{abstract}
A B S T R A C T
Narcolepsy is a sleep disorder characterized by excessive daytime sleepiness and cataplexy (a sudden weakening of posture muscle tone usually triggered by emotion) caused by the loss of orexin neurons in the hypothalamus. Autoimmune mechanisms are implicated in narcolepsy by increased frequency of specific HLA alleles and the presence of specific autoantibody (anti-Tribbles homolog 2 (TRIB2) antibodies) in the sera of patients with narcolepsy. Presently, we passively transferred narcolepsy to naïve mice by injecting intra-cerebra-ventricularly (ICV) pooled IgG positive for anti-TRIB2 antibodies. Narcolepsy-IgG-injected mice had a loss of the NeuN (neuronal marker), synaptophysin (synaptic marker) and orexin-positive neurons in the lateral hypothalamus area in narcolepsy compared to control-IgG-injected mice and these changes were associated with narcolepsy-like immobility attacks at four weeks post injection and with hyperactivity and long term memory deficits in the staircase and novel object recognition tests. Similar behavioral and cognitive deficits are observed in narcoleptic patients. This is the first report of passive transfer of experimental narcolepsy to naïve mice induced by autoantibodies and supports the autoimmune pathogenesis in narcolepsy.
\end{abstract}

(c) 2013 Elsevier Ltd. All rights reserved.

\section{Introduction}

Narcolepsy is a sleep disorder characterized by excessive daytime sleepiness and cataplexy (a sudden weakening of posture muscle tone usually triggered by emotion) caused by the loss of orexin neurons in the hypothalamus [1-4]. Autoimmune mechanisms are implicated in narcolepsy by increased frequency of specific HLA alleles [5] and the presence of specific autoantibody (antiTribbles homolog 2 (TRIB2) antibodies) in the sera of patients with

\footnotetext{
* Corresponding author. Zabludowicz Center for Autoimmune Diseases, Sheba Medical Center, Tel-Hashomer, affiliated to Sackler Medical School, Tel Aviv University, Israel. Tel.: +972 3 5308070; fax: +972 35303673 .

E-mail address: shoenfel@post.tau.ac.il (Y. Shoenfeld).

1 Both first authors contributed equally to this study.
}

narcolepsy [6-8]. In addition to sleep disorders and cataplexy, behavioral and cognitive deficits are also observed in narcoleptic patients [9-11].

The prevalence of narcolepsy with cataplexy is between 25 and 50 per 100,000 people dependent on environmental and genetic factors [12] with the highest prevalence in Japan (0.16\%) [1]. It has been suggested that the cause of narcolepsy is a lack of orexin (hypocretin), an important neurotransmitter in the regulation of the sleep/wake cycle [2]. Though there are genetic animal models, such as orexin knockout mice and dogs with mutations in the orexins receptors [13-15], the etiology of narcolepsy in humans remains unclear. The hypothalamus of postmortem brains from narcolepsy patients show a loss of orexin neurons and the levels of orexin in the cerebrospinal fluid of narcolepsy patients are low or undetectable compared with healthy subjects [16-19]. Orexin is required for body processes such as feeding, cardiovascular 
regulation, emotions, and locomotion. Orexin and histamine act synergistically to promote and maintain arousal behavior $[2,20]$. Removing orexin neurons sets up a mutually inhibitory cycle, which can cause unwanted abrupt transitions to rapid eye movement (REM) sleep and an excessive daytime sleepiness [21,22]. Human genetic data suggests immune factors in narcolepsy are highly associated with risk polymorphisms in the HLA system including the allele DQB1*06:02 in 82-99\% of patients, in contrast to $12-38 \%$ of the healthy population, and the allele DRB1* $15: 01$ $[23,24]$. Protective alleles have been found, such as DQB1*06:01 and DQB1*05:01 [23]. Interestingly, polymorphisms in TCR $\alpha$ chain gene and P2RY11 are also associated with narcolepsy [25,26]. Recent evidence has shown the presence of auto-antibodies against TRIB2, of the tribbles proteins family, found in orexin neurons [6-8]. Using transgenic mice and sera of narcolepsy patient, Cvetkovic-Lopes and coworkers found that the anti-TRIB2 antibodies present in the patients bound directly to the orexin neurons [6]. Our studies in Japanese patients have shown that the titers of anti-TRIB2 antibodies are higher in narcolepsy patients [8] especially if measured close to disease onset [6,7].

In the present study we passively transferred narcolepsy to naïve mice by injecting intra-cerebra-ventricularly (ICV) pooled IgG positive for anti-TRIB2 antibodies. These mice had a selective loss of orexin-positive neurons in the lateral hypothalamus and narcolepsy-like immobility attacks four weeks post injection. Control mice were injected with pooled matched healthy control $\operatorname{IgG}$. This is the first report of passive transfer of experimental narcolepsy to naïve mice induced by autoantibodies and supports the autoimmune pathogenesis in narcolepsy.

\section{Materials and methods}

\subsection{IgG samples}

Blood samples and data related to sleep conditions were collected at the Tokyo Metropolitan Institute of Medical Science (Tokyo, Japan) and Neuropsychiatric Research Institute (Tokyo, Japan). A total of $10 \mathrm{IgG}$ samples from narcolepsy and matched healthy controls purified by using Ab-Capcher (Protenova Co., Ltd. Japan). Narcolepsy patients had also cataplexy, and all of them were positive for anti-TRIB2 by radioligand binding assay. Healthy controls were negative for anti-TRIB2, and they did not have excessive daytime sleepiness or any signs of immunologic abnormalities. Additionally all subjects were positive for the allele DQB1*06:02.

\subsection{Mice}

Thirteen female $\mathrm{C} 3 \mathrm{H}$ mice 4 months old (Harlan Laboratories, IS) were used. The mice were housed in the animal house facility at the Sheba Medical Center, and were maintained at $23 \pm 1{ }^{\circ} \mathrm{C}$, and $12 \mathrm{~h}$ light cycle with free access to food and water. Two groups were injected, the first $(n=6)$ was injected with a total IgG purified from narcoleptic patients, the second group $(n=7)$ was injected with a total IgG from matched healthy controls. The Sheba Medical Center Animal Welfare Committee approved all procedures.

\subsection{Passive transfer ICV}

The passive transfer process was performed according to the protocol described previously [27]. Briefly, $\mathrm{C} 3 \mathrm{H}$ naïve mice were anesthetized by intraperitoneal injection of ketamine $(100 \mathrm{mg} / \mathrm{kg})$ and xylazine $(20 \mathrm{mg} / \mathrm{kg})$. After the skull was carefully exposed, $1 \mu \mathrm{l}$ of the narcoleptic IgG extract or control was slowly infused intra cerebral ventricularly (ICV). The antibody solutions used contained $6 \mathrm{mg}$ protein $/ \mathrm{ml}$. Each mouse received one single injection.

\subsection{Videotaping and scoring of narcoleptic episodes}

Mice were filmed and analyzed for immobility attacks weekly before and after ICV injection by using the NoldusPhenoTyper ${ }^{\circledR}$ cage and EthoVision software ${ }^{\circledR}$ (Noldus Information Technology, Netherlands). Under the same environmental conditions that were mentioned previously, each naïve mouse was recorded individually for $24 \mathrm{~h}$. After the end of the recording process the mouse was injected ICV to with total IgG purified from narcoleptic patients. In parallel, another naive mouse was injected ICV with a total IgG from healthy controls. This protocol was repeated under the same conditions for seven days, after that each mouse that was ICV injected with IgG from narcolpetic patients were recorded serially every week, at days 7, 14, 21 and 28 post injections. Narcoleptic episodes were defined as freezing episodes by using the EthoVision software ${ }^{\circledR}$ and were strictly defined by the following features: (1) abrupt transition from an obvious motor activity; (2) a sustained change in posture maintained throughout the episode; and (3) an abrupt end to the episode with the resumption of obvious purposeful motor activity (essentially a switch between "off" and then "on" states). The exact time recorded on the video for the start and end of each episode was recorded along with the following additional observations: the predominant activity for the 5 seconds (s) preceding and the $10 \mathrm{~s}$ following an episode were categorized as feeding, drinking, ambulating, grooming, burrowing, climbing, or other.

\subsection{Behavioral studies}

To evaluate behavioral changes, the mice were tested in behavioral and cognitive tests including: staircase test, novel object recognition test, Y-maze test, and forced swimming test (FST). The tests were performed at week 5 after ICV administration.

\subsubsection{Staircase test}

This test evaluated exploratory activity and "anxiety -like" behavior. The staircase was placed in a room with constant lighting and isolated from external noise. Each mouse was tested individually. The number of stairs climbed and the number of rears were recorded for a 3 min period. Climbing was defined as each stair on which the mouse placed all four paws; rearing was defined as each instance the mouse rose on hind legs, either on a stair or leaning against the wall. The number of stairs descended was not taken into account. Before each test, the box was cleaned with a diluted alcohol solution to eliminate smells.

\subsubsection{Novel object recognition test}

This test was used to evaluate a long term memory deficit. The apparatus, an open field box $(50 \times 50 \times 20 \mathrm{~cm})$, was constructed from a plywood painted white. Three phases (habituation, training, and retention) were conducted on 2 separate test days. Before training, mice were individually habituated by allowing them to explore the box for $1 \mathrm{~h}$. No data were collected in this phase. During the training session, two identical objects were placed into the box in the northwest and southeast corners (approximately $5 \mathrm{~cm}$ from the walls), $20 \mathrm{~cm}$ away from each other (symmetrically) and then the individual mouse was allowed to explore for $5 \mathrm{~min}$. Exploration of an object was defined as follows: directing the nose to the object at a distance of $\leq 1 \mathrm{~cm}$ and/or touching it with the nose. Turning around or sitting near the object was not considered as exploratory behavior. The time spent to explore each object was recorded. The animals were returned to their home cages immediately after training. During the retention test one of the familiar objects used during training was replaced by a novel object. The mice were placed back into the same box again after a 4 -h interval and allowed 
to explore freely for $5 \mathrm{~min}$. All objects were balanced in term of physical complexity and were emotionally natural. The box and the objects were thoroughly cleaned by $70 \%$ alcohol after each session to avoid possible odorant cues. A preference index, a ratio of the amount of time spent exploring any one of the two items (old and new in the retention session) over the total time spent exploring both objects, was used to measure recognition memory [28]. Individual animals demonstrating insufficient task performance were excluded from later specific statistical analyses for the following reason: non-exploration, which is defined as no object interaction.

\subsubsection{Y-maze test}

The Y maze test was used to study the spatial short term memory, a task requiring hippocampal function and spatial memory. One arm was randomly selected as the "start" arm, and the mouse was placed twice in this arm. On the first trial, lasting for $5 \mathrm{~min}$, one of the other two arms was randomly chosen to be blocked, whereas for the second trial, lasting for $2 \mathrm{~min}$, both arms were open. The two trials were separated by a 2-min interval, during which the mouse was returned to his home cage. The time spent in each of the arms was measured. Between each trial and between each mouse, the maze was cleaned with a $70 \%$ ethanol and dried. Discrimination of spatial novelty was assessed by a preference index: time in the new arm - time in the old arm/time in the new arm + time in the old arm.

\subsubsection{Forced swimming test (FST)}

This test is based on the method of Porsolt et al. to detect depression-like behavior [29]. Depression-like behavior was defined as an immobility (floating) and it was measured in seconds during the 6 min of test, when there was no presence of escapeoriented behaviors such as swimming, jumping, rearing, sniffing, or diving.

\subsection{Histological studies}

At 6 weeks post ICV passive transfer, mice were anesthetized by intraperitoneal injection of ketamine $(100 \mathrm{mg} / \mathrm{kg})$ and xylazine (20 mg/kg) and underwent transcardiac perfusion with phosphate buffer saline followed by perfusion with $4 \%$ paraformaldehyde in PBS. The brains were removed, fixed in $4 \%$ p-formaldehyde in PBS, and cryoprotected by immersion in $30 \%$ sucrose at $4{ }^{\circ} \mathrm{C}$. Frozen coronal sections $(50 \mu \mathrm{m})$ were then cut on a sliding microtome and collected serially and were preserved in a cryoprotectant solution.

For detection of histological changes, brain sections were stained free-floating incubated overnight at $4{ }^{\circ} \mathrm{C}$ with first
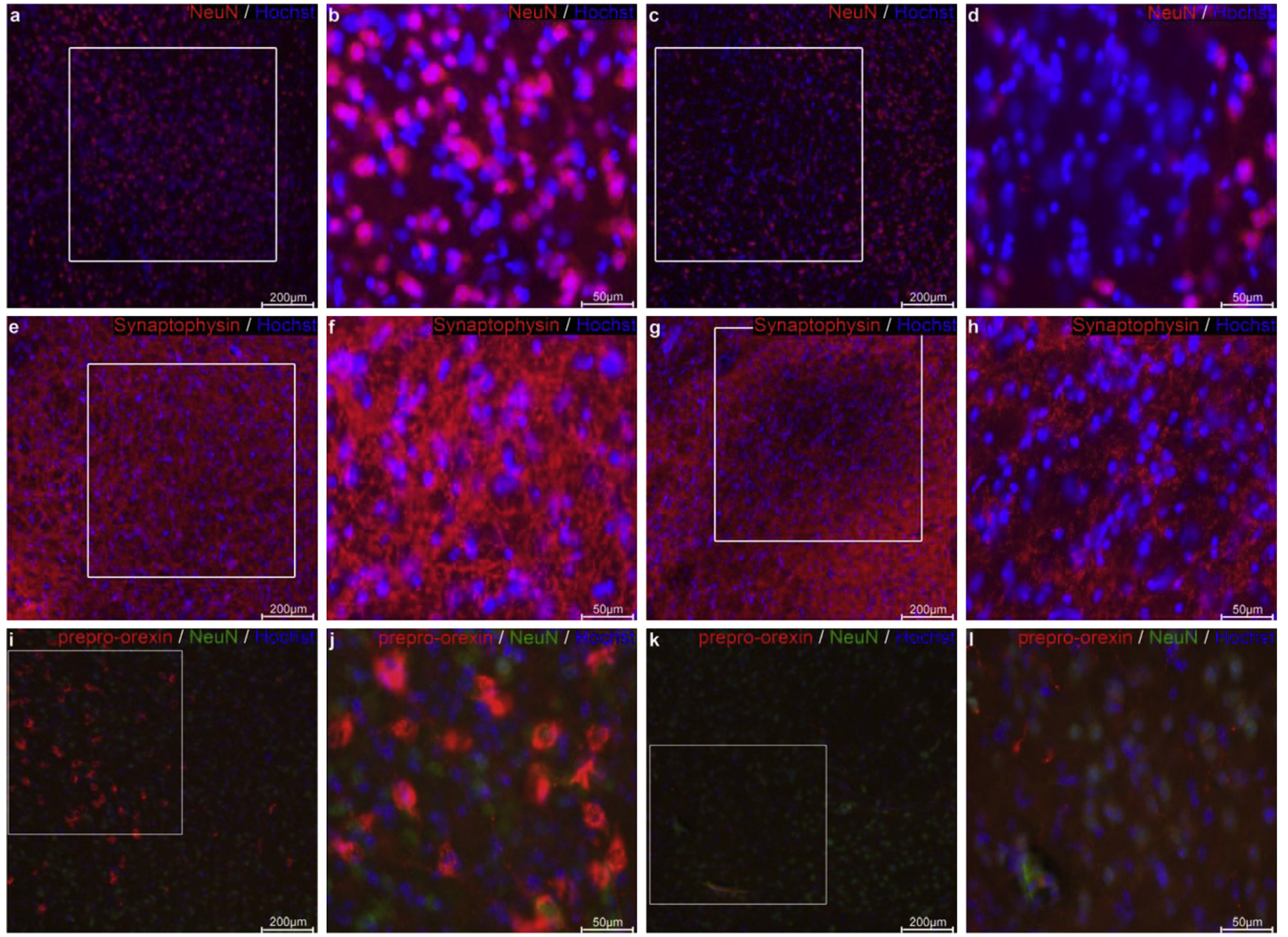

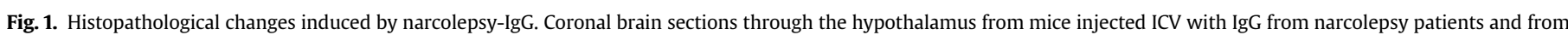

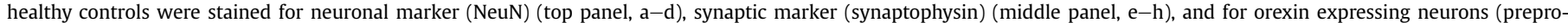

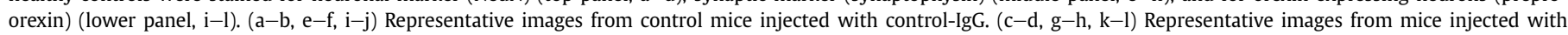

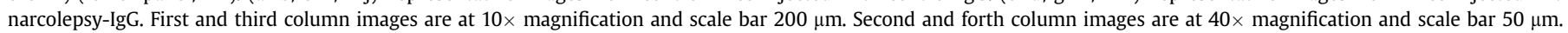


antibodies against neuronal marker (Neuronal Nuclei, NeuN, Chemicon, USA), synaptophysin (SigmaAldrich, USA) or PreproOrexin (Chemicon, USA). After washing, the sections were incubated at a room temperature for $2 \mathrm{~h}$ with the corresponding fluorescent chromogens-conjugated secondary antibody. Counter staining was performed with Hoechst.

\subsection{Statistical analysis}

The $\chi^{2}$ test for categorical variable was applied for comparison between groups. Continuous values among groups were tested using ANOVA. The analysis was performed using the SPSS 17.0 software. Results are presented as averages \pm standard error of the mean, and in percentages. Differences among the cases and controls in all the variables were established by Chi-square or Fisher's tests as appropriate. Continuous values among groups were tested using $T$-test or ANOVA. A level of $5 \%$ was used to define statistical significance $(p<0.05)$.

\section{Results}

\subsection{Histopathological changes induced by narcoleptic $\operatorname{Ig} G$}

Brain sections through the hypothalamus from narcolepsy and control mice were stained for neuronal and synaptic markers and for orexin expressing neurons and representative data are presented in Fig. 1. There was a loss of the neuronal marker (Neronal Nuclei, NeuN) (Fig. 1a-d) and the synaptic marker (synaptophysin) (Fig. $1 \mathrm{e}-\mathrm{h}$ ) in the lateral hypothalamus area in narcolepsy mice compared to controls. The most striking difference between the 2 groups was a significant loss of orexin-positive neurons (preproorexin staining) in the lateral hypothalamic area in narcolepsy-IgG compared to control-IgG mice (Fig. $1 \mathrm{j}-1$ ).

\subsection{Behavioral characterization of narcolepsy-like episodes}

Mice were filmed and analyzed weekly before and after ICV injection of the Abs. For each mouse the $12 \mathrm{~h}$ of the dark phase were analyzed for immobility/freezing episodes. Narcolepsy-like episodes were not observed before the ICV injection of Abs. Narcolepsy/cataplexy-like immobility attacks were recorded in narcolepsy mice 4 weeks post injection but not before. The number and time of episodes for each mouse are summarized (Table 1).

\subsection{Behavioral and cognitive performance}

Narcolepsy mice and controls were tested in the staircase test and (Fig. 2a). Narcolepsy mice were significantly hyperactive as measured in both stair-climbing and rearing parameters $(p<0.005$

\section{Table 1}

Characterization of the number and duration of sleeping attacks during the first $12 \mathrm{~h}$ of the light phase in mice injected with IgG from narcolepsy patients. The exact time recorded on the video for the start and end of each episode was recorded along with the following additional observations: the predominant activity for the 5 seconds (s) preceding and the $10 \mathrm{~s}$ following an episode were categorized as feeding, drinking, ambulating, grooming, burrowing, climbing, or other.

\begin{tabular}{lll}
\hline Mouse & Sleeping attacks $N$ & $\begin{array}{l}\text { Attack duration } \\
\text { (average, sec) }\end{array}$ \\
\hline 1 & 4 & 88 \\
2 & 3 & 66 \\
3 & 0 & - \\
4 & 1 & 210 \\
5 & 2 & 464 \\
6 & 2 & 188 \\
\hline
\end{tabular}

by $t$-test) in the staircase test. The results of cognitive performance in the novel object recognition test are presented as discrimination index for novel object as a measure for long term recognition memory (Fig. 2b). There was a significant preference for attention to the new object in the control group compared to the narcolepsy group (34\% vs. $-16 \%$ additional percent time spent in near the novel object, $p=0.00001$ by $t$-test). This suggests specific visual recognition memory impairment in the narcolepsy mice. Cognitive performance in the Y-maze test is presented as preference index for new (additional percent time spent in the novel arm) as a measure for short term spatial novelty memory (Fig. 2c). There was no significant difference between the narcolepsy and the control groups in the additional time spent in the new arm ( $45 \% \mathrm{vs.} 18 \%, p=0.32$ by $t$-test). In the forced swimming test the narcolepsy mice performed poorly and exhibited significant depression-like behavior compared to controls (Fig. 2d). Average immobility times of the control mice vs. narcolepsy mice were $123.1 \pm 28.1$ vs. $219.4 \pm 31.4$ $(p=0.00003$ by $t$-test $)$.

\section{Discussion}

This study demonstrates the passive transfer of orexin neuron loss and narcolepsy-like behavioral changes by anti-TRIB2 positive narcolepsy patients IgG. The histological data showed a loss of both neuronal and synaptic markers demonstrating a neurodegenerative process in the hypothalamus and a loss of the prepro-orexin peptide in the mice injected with $\operatorname{IgG}$ from narcoleptic patients. Preproorexin is the precursor of the two kinds of orexins, A and B, and it is exclusively produced in the lateral hypothalamic orexin neurons $[2,22]$. This loss of orexin neurons is similar to what has been described in postmortem brains of narcoleptic patients $[5,18,19]$. Loss of the NeuN marker may indicate more extensive damage to neurons in this area. The loss of synaptophysin is compatible with a decreased neuronal activity and signaling. The loss of synapses in the lateral hypothalamic area is probably the consequence of the loss of orexin neurons in this area and may be related to with other neurotransmitters that are produced in the orexin neurons such as glutamate [30].

There are several animal models of narcolepsy, most of them are knockout mice with lack of orexin or orexin receptors, but the models that best resemble the symptoms characteristic of human narcolepsy are those with a loss of the orexin neurons $[13,23,30-$ 32 ]. The orexin/ataxin-3 hemizygous mice show the reduction of orexin neurons by ataxin-3 accumulations after birth, and these mice regarded as a good model for human narcolepsy [33]. This may indicate that the clinical signs and symptoms of human narcolepsy depend on the loss of orexin neurons and all their functions rather than just the loss of orexin. In 2004, Smith et al. described an animal model by intra-peritoneal injection with total IgG from narcoleptic patients to healthy mice [34]. They described the cessation of movements from a few seconds to 1 min during activities such as grooming in the injected mice, which are very similar to the behavioral pattern that we found in our narcolepsy mice. Mice injected with IgG from narcoleptic patients, develop cognitive and behavioral impairments compatible with narcoleptic patients that have alterations in their cognitive and behavioral functions [35]. The narcoleptic mice showed hyperactivity, long term memory deficits and depression. In humans, it has been reported that children with attention deficit hyperactivity disorder (ADHD) have a similar sleep pattern to narcolepsy patients, characterized by a period of sleepiness during the day and abnormal pattern of REM cycle [11,36,37]. In a case control-study Jara et al., showed that the frequency of depression in narcolepsy patients was higher than in healthy controls, and that it was not dependent on the presence of cataplexy [38]. Some authors suggest that in 

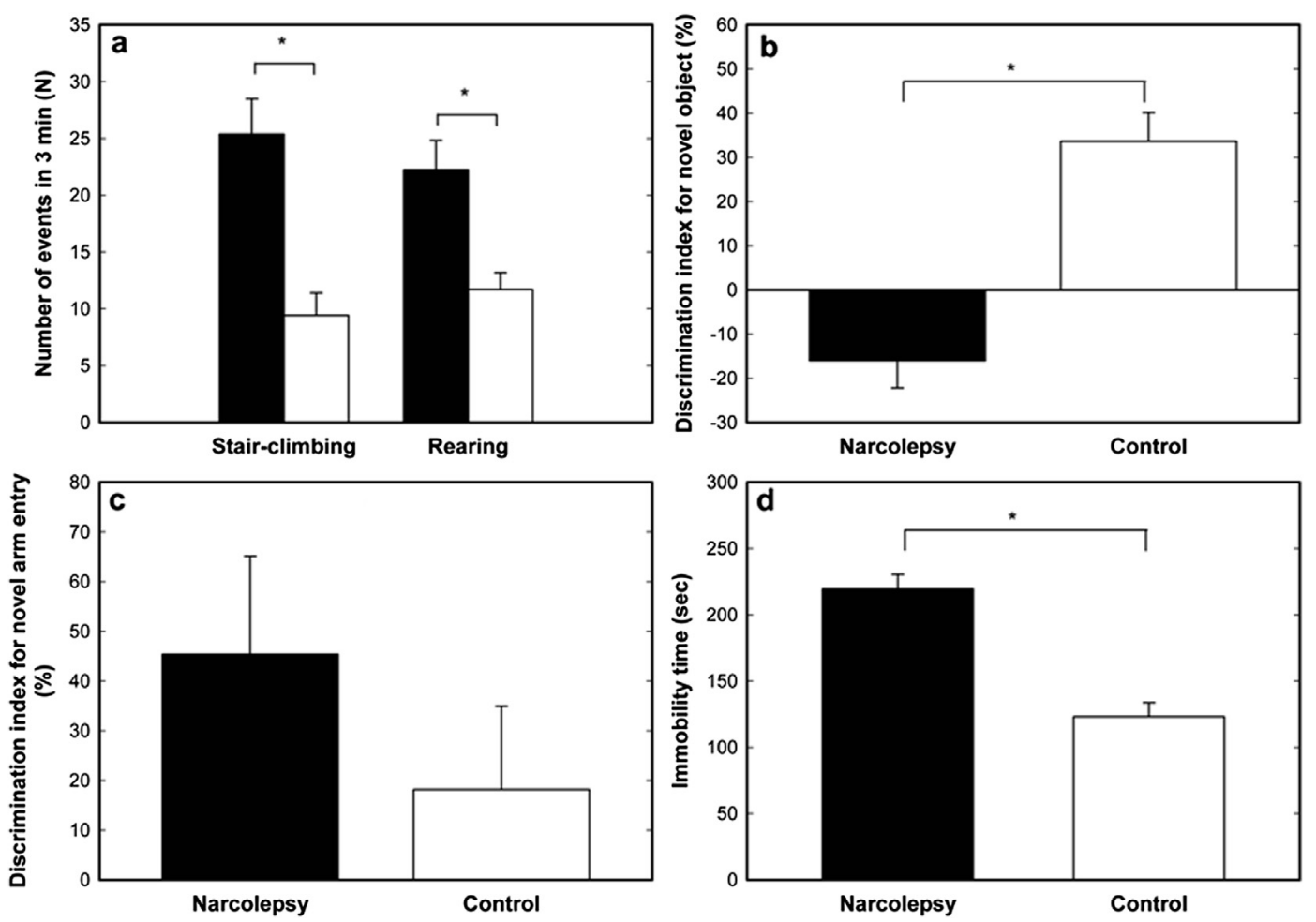

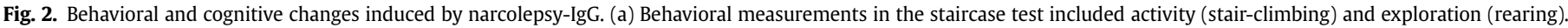

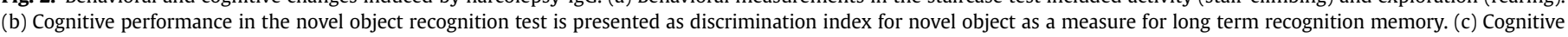

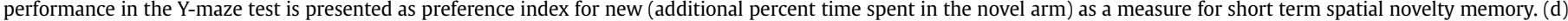

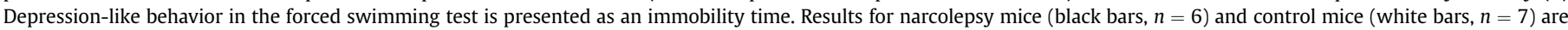
presented as mean \pm SEM. ${ }^{*} P<0.05$ compared to controls (unpaired $t$ test).

narcolepsy patients the depression and the associated anxiety may be a secondary outcome to the social consequences and the perception of a hostile environment $[10,38]$. However our results using a mouse model suggest that this manifestation may be a primary manifestation of the disease. The normal production of orexin is linked to the normal function of the limbic and dopaminergic systems related to the production of neurotransmitters such as norepinephrine, serotonin and histamine [2,22]. Burgess et al. described a change in the expression pattern of dopamine receptors in orexin knockout mice and they linked this alteration with the presence of sleep pattern changes and cataplexy [39]. However, the dopaminergic system is also important in the other processes such as making decisions and learning and deficits in these functions have been also demonstrated in narcolepsy [9]. In line with all these changes we also found memory impairments in the narcolepsy-IgG injected animals. There are several studies in narcolepsy patients that show alteration in attention and reduced learning, recognition and memory capacities [40]. There are reports of poor performance in the long term memory tests and a normal performance in the short term memory tests [37], similarly to what we found in the narcolepsy mice in the novel object recognition and Y-maze tests. As Lloyd et al. have described, there are several manifestations in children with sleep disorders that include learning difficulties, hyperactivity and mood changes [41].

\section{Final comments}

This paper is part of a dedicated issue of the Journal of Autoimmunity to honor the many contributions of Professor Abul Abbas. It is a particular pleasure for our group to contribute to this issue because of Abul's long commitment to the many Congresses of
Autoimmunity. The Congress of Autoimmunity is an international meeting that occurs every two years. The goal of the Congress, like so many international meetings, has the broad mission of bringing together scholars to present their work and improve our understanding of autoimmunity. It has, however, served a much larger purpose which is that of widespread education in immunology to our younger colleagues and in this respect, Abul Abbas has graciously volunteered and has led with considerable enthusiasm a full-day meeting devoted just to an update on cutting-edge immunology. It is a session which is greeted with incredible enthusiasm. The success of the Congress which have included symposia dealing with geoepidemiology, new treatments, gender susceptibilities, genomics, pregnancy loss, differential diagnosis of unique and rare syndromes, epigenetics, twins, environmental factors and of course cellular immunology; all have succeeded in their own dedicated sessions that come after the initial introductory immunology course of Abul Abbas and for this we thank him [42-64]. The next Congress of Autoimmunity will be in Nice, France in March 2014 and we look forward to another cutting-edge presentation by Abul. It is therefore with humility and gratitude that this paper be included in this special issue.

\section{Conclusions}

We presently demonstrated that antibodies present in the sera of narcoleptic patients induce narcolepsy-like episodes in naïve mice after ICV injection. The narcoleptic patients' sera were positive for anti-TRIB2, which reinforces the hypothesis that TRIB2 may be a major auto-antigen in subgroup of narcolepsy that induces the destruction of orexin neurons in the brain of narcolepsy patients. It remains unclear how the antibodies responsible for the loss of 
orexin neurons penetrate the blood brain barrier. The recognition that narcolepsy is an autoimmune disorder has important clinical implications. Similarly to type I diabetes, the time window in which to save orexin neurons from autoimmune destruction may be a very narrow as demonstrated by a single injection in the present study. Early detection and prompt therapy of narcolepsy are indicated.

\section{Competing financial interests}

The authors declare no competing financial interests.

\section{Acknowledgments}

This study was supported by the Federico Foundation.

\section{References}

[1] Akintomide GS, Rickards H. Narcolepsy: a review. Neuropsychiatr Dis Treat 2011;7:507-18.

[2] Sakurai T, Mieda M, Tsujino N. The orexin system: roles in sleep/wake regulation. Ann N Y Acad Sci 2010;1200:149-61.

[3] Zeitzer JM, Nishino S, Mignot E. The neurobiology of hypocretins (orexins), narcolepsy and related therapeutic interventions. Trends Pharmacol Sci 2006;27:368-74.

[4] Dauvilliers Y, Arnulf I, Mignot E. Narcolepsy with cataplexy. Lancet 2007;369: 499-511.

[5] Fontana A, Gast H, Reith W, Recher M, Birchler T, Bassetti CL. Narcolepsy: autoimmunity, effector $\mathrm{T}$ cell activation due to infection, or $\mathrm{T}$ cell independent, major histocompatibility complex class II induced neuronal loss? Brain 2010;133:1300-11.

[6] Cvetkovic-Lopes V, Bayer L, Dorsaz S, Maret S, Pradervand S, Dauvilliers Y, et al. Elevated Tribbles homolog 2-specific antibody levels in narcolepsy patients. J Clin Invest 2010;120:713-9.

[7] Kawashima M, Lin L, Tanaka S, Jennum P, Knudsen S, Nevsimalova S, et al. Anti-Tribbles homolog 2 (TRIB2) autoantibodies in narcolepsy are associated with recent onset of cataplexy. Sleep 2010;33:869-74.

[8] Toyoda H, Tanaka S, Miyagawa T, Honda Y, Tokunaga K, Honda M. AntiTribbles homolog 2 autoantibodies in Japanese patients with narcolepsy. Sleep 2010;33:875-8.

[9] Delazer M, Hogl B, Zamarian L, Wenter J, Gschliesser V, Ehrmann L, et al. Executive functions, information sampling, and decision making in narcolepsy with cataplexy. Neuropsychology 2011;25:477-87.

[10] Fortuyn HA, Mulders PC, Renier WO, Buitelaar JK, Overeem S. Narcolepsy and psychiatry: an evolving association of increasing interest. Sleep Med 2011;12: 714-9.

[11] Miano S, Parisi P, Villa MP. The sleep phenotypes of attention deficit hyperactivity disorder: the role of arousal during sleep and implications for treatment. Med Hypotheses 2012;79:147-53.

[12] Longstreth Jr WT, Koepsell TD, Ton TG, Hendrickson AF, van Belle G. The epidemiology of narcolepsy. Sleep 2007;30:13-26.

[13] Chemelli RM, Willie JT, Sinton CM, Elmquist JK, Scammell T, Lee C, et al. Narcolepsy in orexin knockout mice: molecular genetics of sleep regulation. Cell 1999;98:437-51.

[14] Lin L, Faraco J, Li R, Kadotani H, Rogers W, Lin X, et al. The sleep disorder canine narcolepsy is caused by a mutation in the hypocretin (orexin) receptor 2 gene. Cell 1999;98:365-76.

[15] Scammell TE, Willie JT, Guilleminault C, Siegel JM. A consensus definition of cataplexy in mouse models of narcolepsy. Sleep 2009;32:111-6.

[16] Mignot E, Lammers GJ, Ripley B, Okun M, Nevsimalova S, Overeem S, et al. The role of cerebrospinal fluid hypocretin measurement in the diagnosis of narcolepsy and other hypersomnias. Arch Neurol 2002;59:1553-62.

[17] Nishino S, Ripley B, Overeem S, Nevsimalova S, Lammers GJ, Vankova J, et al. Low cerebrospinal fluid hypocretin (Orexin) and altered energy homeostasis in human narcolepsy. Ann Neurol 2001;50:381-8.

[18] Peyron C, Faraco J, Rogers W, Ripley B, Overeem S, Charnay Y, et al. A mutation in a case of early onset narcolepsy and a generalized absence of hypocretin peptides in human narcoleptic brains. Nat Med 2000;6:991-7.

[19] Thannickal TC, Siegel JM, Nienhuis R, Moore RY. Pattern of hypocretin (orexin) soma and axon loss, and gliosis, in human narcolepsy. Brain Pathol 2003;13: 340-51.

[20] Anaclet C, Parmentier R, Ouk K, Guidon G, Buda C, Sastre JP, et al. Orexin/ hypocretin and histamine: distinct roles in the control of wakefulness demonstrated using knock-out mouse models. J Neurosci 2009;29:14423-38.

[21] Huang W, Ramsey KM, Marcheva B, Bass J. Circadian rhythms, sleep, and metabolism. J Clin Invest 2011;121:2133-41.

[22] Ohno K, Sakurai T. Orexin neuronal circuitry: role in the regulation of sleep and wakefulness. Front Neuroendocrinol 2008;29:70-87.
[23] Kornum BR, Faraco J, Mignot E. Narcolepsy with hypocretin/orexin deficiency, infections and autoimmunity of the brain. Curr Opin Neurobiol 2011;21:897-903.

[24] Mignot E, Lin L, Rogers W, Honda Y, Qiu X, Lin X, et al. Complex HLA-DR and-DQ interactions confer risk of narcolepsy-cataplexy in three ethnic groups. Am J Hum Genet 2001;68:686-99.

[25] Hallmayer J, Faraco J, Lin L, Hesselson S, Winkelmann J, Kawashima M, et al. Narcolepsy is strongly associated with the T-cell receptor alpha locus. Nat Genet 2009;41:708-11.

[26] Kornum BR, Kawashima M, Faraco J, Lin L, Rico T], Hesselson S, et al. Common variants in P2RY11 are associated with narcolepsy. Nat Genet 2011;43:66-71.

[27] Katzav A, Solodeev I, Brodsky O, Chapman J, Pick CG, Blank M, et al. Induction of autoimmune depression in mice by anti-ribosomal $\mathrm{P}$ antibodies via the limbic system. Arthritis Rheum 2007;56:938-48.

[28] Dix SL, Aggleton JP. Extending the spontaneous preference test of recognition: evidence of object-location and object-context recognition. Behav Brain Res 1999;99:191-200.

[29] Porsolt RD, Bertin A, Jalfre M. Behavioral despair in mice: a primary screening test for antidepressants. Arch Int Pharmacodyn Ther 1977;229:327-36.

[30] Henny P, Brischoux F, Mainville L, Stroh T, Jones BE. Immunohistochemical evidence for synaptic release of glutamate from orexin terminals in the locus coeruleus. Neuroscience 2010;169:1150-7.

[31] Fronczek R, Baumann CR, Lammers GJ, Bassetti CL, Overeem S. Hypocretin/ orexin disturbances in neurological disorders. Sleep Med Rev 2009:13:9-22.

[32] Chen L, Brown RE, McKenna JT, McCarley RW. Animal models of narcolepsy. CNS Neurol Disord Drug Targets 2009;8:296-308.

[33] Hara J, Beuckmann CT, Nambu T, Willie JT, Chemelli RM, Sinton CM, et al. Genetic ablation of orexin neurons in mice results in narcolepsy, hypophagia, and obesity. Neuron 2001;30:345-54.

[34] Smith AJ, Jackson MW, Neufing P, McEvoy RD, Gordon TP. A functional autoantibody in narcolepsy. Lancet 2004;364:2122-4.

[35] Wurtman RJ. Narcolepsy and the hypocretins. Metabolism 2006;55:S36-9.

[36] Peraita-Adrados R, Garcia-Penas JJ, Ruiz-Falco L, Gutierrez-Solana L, LopezEsteban P, Vicario JL, et al. Clinical, polysomnographic and laboratory characteristics of narcolepsy-cataplexy in a sample of children and adolescents. Sleep Med 2011;12:24-7.

[37] Walters AS, Silvestri R, Zucconi M, Chandrashekariah R, Konofal E. Review of the possible relationship and hypothetical links between attention deficit hyperactivity disorder (ADHD) and the simple sleep related movement disorders, parasomnias, hypersomnias, and circadian rhythm disorders. J Clin Sleep Med 2008;4:591-600.

[38] Jara CO, Popp R, Zulley J, Hajak G, Geisler P. Determinants of depressive symptoms in narcoleptic patients with and without cataplexy. J Nerv Ment Dis 2011;199:329-34.

[39] Burgess CR, Tse G, Gillis L, Peever JH. Dopaminergic regulation of sleep and cataplexy in a murine model of narcolepsy. Sleep 2010;33:1295-304.

[40] Fulda S, Schulz H. Cognitive dysfunction in sleep disorders. Sleep Med Rev 2001;5:423-45.

[41] Lloyd R, Tippmann-Peikert M, Slocumb N, Kotagal S. Characteristics of REM sleep behavior disorder in childhood. J Clin Sleep Med 2012;8:127-31.

[42] Oke V, Wahren-Herlenius M. The immunobiology of Ro52 (TRIM21) in autoimmunity: a critical review. J Autoimmun 2012;39:77-82.

[43] Chang C. Neonatal autoimmune diseases: a critical review. J Autoimmun 2012;38:J223-38.

[44] Chighizola C, Meroni PL. The role of environmental estrogens and autoimmunity. Autoimmun Rev 2012;11:A493-501.

[45] Seror R, Bootsma H, Bowman SJ, Dorner T, Gottenberg JE, Mariette X, et al. Outcome measures for primary Sjogren's syndrome. J Autoimmun 2012;39: 97-102.

[46] Lee TP, Chiang BL. Sex differences in spontaneous versus induced animal models of autoimmunity. Autoimmun Rev 2012;11:A422-9.

[47] Ice JA, Li H, Adrianto I, Lin PC, Kelly JA, Montgomery CG, et al. Genetics of Sjogren's syndrome in the genome-wide association era. J Autoimmun 2012;39:57-63.

[48] Comarmond C, Plaisier E, Dahan K, Mirault T, Emmerich J, Amoura Z, et al. Anti TNF- $\alpha$ in refractory Takayasu's arteritis: cases series and review of the literature. Autoimmun Rev 2012;11:678-84.

[49] Carp HJ, Selmi C, Shoenfeld Y. The autoimmune bases of infertility and pregnancy loss. J Autoimmun 2012;38:J266-74.

[50] Shelly S, Boaz M, Orbach H. Prolactin and autoimmunity. Autoimmun Rev 2012;11:A465-70.

[51] Sawalha AH, Wang L, Nadig A, Somers EC, McCune WJ, Hughes T, et al., Michigan Lupus Cohort. Sex-specific differences in the relationship between genetic susceptibility, T cell DNA demethylation and lupus flare severity. J Autoimmun 2012;38:J216-22.

[52] Oertelt-Prigione $S$. The influence of sex and gender on the immune response. Autoimmun Rev 2012;11:A479-85.

[53] Amur S, Parekh A, Mummaneni P. Sex differences and genomics in autoimmune diseases. J Autoimmun 38:J254-65.

[54] Oertelt-Prigione S. Immunology and the menstrual cycle. Autoimmun Rev 2012;11:A486-92.

[55] Bogdanos DP, Smyk DS, Rigopoulou EI, Mytilinaiou MG, Heneghan MA, Selmi C, et al. Twin studies in autoimmune disease: genetics, gender and environment. J Autoimmun 2012;38:J156-69.

[56] Moroni L, Bianchi I, Lleo A. Geoepidemiology, gender and autoimmune disease. Autoimmun Rev 2012;11:A386-92. 
[57] Strickland FM, Hewagama A, Lu Q, Wu A, Hinderer R, Webb R, et al. Environmental exposure, estrogen and two $\mathrm{X}$ chromosomes are required for disease development in an epigenetic model of lupus. J Autoimmun 38:J135-43.

[58] Nussinovitch U, Shoenfeld Y. The role of gender and organ specific autoimmunity. Autoimmun Rev 2012;11:A377-85.

[59] Lidar M, Langevitz P. Pregnancy issues in scleroderma. Autoimmun Rev 2012;11:A515-9.

[60] Selmi C, Brunetta E, Raimondo MG, Meroni PL. The X chromosome and the sex ratio of autoimmunity. Autoimmun Rev 2012:A531-7.
[61] Palazzi C, Buskila D, D’Angelo S, D’Amico E, Olivieri I. Autoantibodies in patients with chronic hepatitis $C$ virus infection: pitfalls for the diagnosis of rheumatic diseases. Autoimmun Rev 2012;11:659-63.

[62] Singh RP, Waldron RT, Hahn BH. Genes, tolerance and systemic autoimmunity. Autoimmun Rev 2012;11:664-9.

[63] Petrikova J, Lazurova I. Ovarian failure and polycystic ovary syndrome. Autoimmun Rev 2012;11:A471-8.

[64] Ostensen M, Villiger PM, Forger F. Interaction of pregnancy and autoimmune rheumatic disease. Autoimmun Rev 2012;11:A437-46. 